\title{
Nutritive Supplements - Help or Harm for Breast Cancer Patients?
}

\author{
Karsten Muenstedt Samer El-Safadi \\ Department for Gynecology and Obstetrics, University Hospital Giessen and Marburg GmbH, Giessen, Germany
}

\section{Keywords}

Micronutrient . Multivitamin products - Supplement . Breast cancer · Prevention

\section{Summary}

Considerable numbers of patients and physicians believe that micronutrients may be useful with respect to prevention and treatment of breast cancer. However, the analysis of the literature shows that basic information on nutritional demands in cancer patients is lacking. It is unknown whether there is an increased demand of micronutrients in cancer patients in general and if there is an even more increased demand during the various types of treatment. As a result, there are only limited positive findings. Higher calcium intake in premenopausal women and higher intake of vitamin $D$ seem to be able to lower breast cancer incidence. Vitamin E (800 IU per day) was found to have a modest effect on hot flashes during tamoxifen treatment. However, there are potential side effects especially when micronutrients are administered in high or very high doses. There is increasing evidence that dose-effect relationships are not linear but U-shaped. It seems that two thresholds exist for adverse effect, one at low doses for undersupply, and another at high doses for toxicity. Thus, arbitrary high-dose administration of micronutrients should be avoided. Supplementation of normal doses seems to be safe and acceptable from the medical point of view.

\section{Introduction}

Micronutrients are defined as substances which the human organism cannot synthesize but that are needed in very small quantities for normal body function (generally less than $100 \mu \mathrm{g} /$ day). Microminerals or trace elements (e.g. iron, cobalt, chromium, copper, iodine, manganese, selenium, zinc, molybdenum) and various vitamins can thus be considered as

\author{
Schlüsselwörter \\ Mikronährstoffe · Multivitaminprodukte · \\ Supplementierung · Brustkrebs · Prävention
}

\section{Zusammenfassung}

Viele Ärzte und Patienten glauben, dass Mikronährstoffe im Hinblick auf die Vorbeugung und Behandlung von Brustkrebs nützlich sind. Eine Analyse der Literatur dagegen zeigt, dass grundlegende Untersuchungen zu diesem Thema fehlen. Bislang ist unbekannt, ob Krebspatienten überhaupt einen gesteigerten Bedarf haben und ob während den verschiedenen Behandlungselementen ein erhöhter Bedarf besteht. Entsprechend gibt es nur begrenzte Erkenntnisse. Eine vermehrte Einnahme von Kalzium und Vitamin D scheint die Brustkrebsinzidenz zu senken. Es wurde gezeigt, dass Vitamin E (800 IU pro Tag) einen schwach positiven Effekt im Hinblick auf Hitzewallungen hat. Allerdings gibt es Hinweise auf negative Wirkungen, insbesondere wenn Vitamine in hohen Dosen eingenommen werden, denn es gibt zunehmend Hinweise dafür, dass Dosis-Wirkungsbeziehungen nicht linear, sondern U-förmig verlaufen. Das bedeutet, dass es zwei Schwellenwerte gibt: einen für die Unterversorgung und einen für die Toxizität. Entsprechend muss eine unreflektierte, hochdosierte Gabe von Mikronährstoffen vermieden werden. Dagegen erscheint eine Supplementierung in normalen Dosen als sicher und akzeptabel.

micronutrients and must be obtained from the diet. The fact that micronutrient deficiency diseases are widespread and affect large numbers of people especially in developing countries clearly underlines the importance of micronutrients. An estimated 2 billion people worldwide suffer from some kind of micronutrient deficiency which may cause a wide range of disorders and could also affect the incidence of cancer and patient survival [1].

\section{KARGER}

Fax +497614520714

Information@Karger.de

www.karger.com (c) 2010 S. Karger GmbH, Freiburg

Accessible online at

www.karger.com/brc 
The reasons behind the widespread use of micronutrients as a part of complementary and alternative medicine (CAM) have not yet been investigated. However, what may have led to the fact that administration of micronutrients has become one of the most frequently used methods by the general population are the high prevalence of micronutrient deficiency diseases in general, the possibility that undetected micronutrient deficiencies could exist, the fact that micronutrient deficiencies could be associated with cancer incidence, the belief that there are increased requirements of micronutrients during cancer treatment, and the possibility that optimal supplementation with micronutrients could improve the chances of survival. According to the National Health and Nutrition Examination Survey (NHANES) 1999$2000,52 \%$ of the adults in the USA reported taking a dietary supplement in the past month, and $35 \%$ reported regular use of multivitamin-multimineral products [2]. In the field of oncology, an estimated $45-80 \%$ of breast cancer patients use antioxidant supplements after diagnosis and during breast cancer treatment [3].

The question is whether this use of micronutrients has positive or negative effects on the various clinical situations - the incidence of breast cancer, the time of active cancer therapy with the various cancer treatments, and follow-up time. Very important questions are whether supplementation with micronutrients could improve the chances of survival and lower the risk of recurrence. In order to give an answer to these questions, each of these situations will be looked at separately.

\section{Incidence of Breast Cancer}

The effects of micronutrient administration on the incidence of cancer including breast cancer have been studied for a long time. Accordingly, it was possible to perform systematic reviews and meta-analyses on the various trials, providing a good overview of the effects of micronutrients. The results of these analyses are summarized below.

Higher calcium intake in premenopausal women was associated with a decreased risk for breast cancer [4]. Also a trend towards fewer cases of breast cancer with higher intake of vitamin D ( $\geq 400$ IU/day) was found [5]. However, vitamin D does not necessarily have to be supplemented - it can be produced in the skin and kidneys if there is sufficient exposure to solar ultraviolet-B radiation (attention: higher risk of melanoma). Furthermore, vitamin D was found to protect against more than 17 different other types of cancer [6].

Vitamin E supplementation was not associated with a positive influence on breast cancer incidence [7]. No effect of beta-carotene supplementation was observed on the incidence of breast cancer either but it was associated with increased risk of lung cancer and gastric cancer at doses of 20-30 mg per day in smokers and asbestos workers. Thus beta-carotene supplementation for cancer prevention can not be recommended [8]. Similarly, no support for an overall relationship between folate intake or blood folate levels and breast cancer risk was found. Adequate folate intake may only reduce the increased risk of breast cancer that has been associated with moderate or high alcohol consumption [9]. Also, selenium and zinc serum levels have not been found to be associated with a decreased risk of breast cancer [10].

Studies also suggest that a high intake of vitamin $\mathrm{C}$ before diagnosis of breast cancer may be beneficial regarding breast cancer mortality [11].

\section{Micronutrients during Systemic Treatment of Breast Cancer}

Interestingly, there seem to be only few analyses on patients' nutritional requirements regarding micronutrients during surgery. Similarly, there are no valid studies on patients' requirements during chemotherapy. Chemotherapy may also lower the levels of antioxidants by affecting dietary intake, which is supported by preliminary data on vitamins $\mathrm{C}$ and $\mathrm{E}$, selenium, and beta-carotene showing that chemotherapy lowers the total antioxidant status [11]. Cancer patients seem to be depleted of antioxidants before initiation of treatment, perhaps because cancer cells use antioxidant vitamins more efficiently than healthy cells, thus depleting circulating plasma levels of antioxidants, which suggests that low antioxidant status may be associated with neoplastic activity and subsequent poor health [11]. Accordingly, a declining cancer cell burden may lead to improved antioxidant levels. However, some findings are difficult to interpret. For example, it was found that TRAP (a measure of total antioxidant capacity) levels decreased, while the individual antioxidants showed no consistent changes. Perhaps other factors than the known antioxidants contribute to changes in the total antioxidant status of the body during chemotherapy [11].

Experimental studies show that antioxidant vitamins selectively induce apoptosis in cancer cells but not in normal cells and prevent angiogenesis and metastatic spread which suggests a potential role in cancer therapy [12]. But in vitro evidence must prove to be valid in clinical trials. A recent review on the efficacy of antioxidant supplements during breast cancer treatment by Greenlee et al. [3] identified a total of 19 articles (9 randomized controlled trials, 4 non-randomized controlled trials, and 6 single-arm trials). The results of their analyses can be summarized as follows: i) vitamin E does not prevent doxorubicin-induced alopecia or doxorubicin-induced cardiotoxicity; ii) vitamin E (800 IU per day) may have a modest effect on hot flashes among breast cancer patients taking tamoxifen - on average one less hot flash per day; iii) patients taking multivitamins during radiation therapy reported significantly higher rates of fatigue compared to those on placebo ( 25 vs. $0 \%)$; iv) glutamine $(2.5 \mathrm{~g}$ per day in a swish 
and swallow solution) was found to reduce the incidence (38.7 vs. $49.7 \%$ ) and severity of oral mucositis (1.2 vs. $6.7 \%$ ) during anthracycline-based chemotherapy. Another trial, however, found no effect on stomatitis and diarrhea.

Three well designed, randomized, placebo-controlled trials examined the effect of soy isoflavones on hot flashes in postmenopausal women with a history of breast cancer, some of whom were on hormonal therapy with tamoxifen or raloxifen. All of them failed to show any effect of soy intake on the frequency or intensity of hot flashes. Vitamin C (ascorbic acid, $3 \mathrm{~g}$ per day) administration did not lead to improved survival (5-year disease-free survival rates: $48 \%$ in ascorbic acid group versus $50 \%$ in control group). One large-scale observational study of breast cancer patients using high-dose combination antioxidants during treatment showed a trend towards decreased survival.

An interesting study which was not included in the referred review showed that vitamin D deficiency may be associated with poor outcome in breast cancer [13]. As Greenlee et al. [3] only focused on breast cancer and only identified a few relevant studies, it seems appropriate to look at data from other tumor entities as well. Here, Block et al. [14] analyzed the impact of antioxidant supplementation on chemotherapeutic toxicity. They found that the majority of the published studies show that antioxidants lead to significantly reduced toxicity during chemotherapy. These findings refer to neurotoxicity in cases of platinum-based chemotherapies, myelosuppression, diarrhea, nausea/vomiting, nephrotoxicity, and ototoxicity. Regarding neurotoxicity, 4 of 5 vitamin E studies showed a statistically significant reduction with doses ranging from 300-600 mg of vitamin E across various cancer types. Regarding tumor response and survival, Block et al. [14] found that most studies reported same or better response than the control group and that no studies reported significantly worse survival or response in the antioxidant supplement group. This conclusion is similar to the interpretation of another analysis of the studies, which finds that antioxidants and other nutrients do not interfere with chemotherapy and can increase tumor cell kill and improve survival [15, 16]. However, clinical studies on the effect of antioxidants on cancer treatment are limited in number and size, and the quality of most trials is low. All but one of the studies included less than 300 patients. Thus, the limited number and power of the studies make it impossible to rule out the possibility that antioxidants have no effect or even a negative effect on chemotherapy toxicities.

\section{Micronutrients during Radiotherapy Treatment of Breast Cancer}

There is little knowledge about the influence of micronutrients on radiotherapy, and there are no systematic reviews. At present, there are two opposing hypotheses regarding the use of antioxidants during radiation therapy. According to one hypothesis, supplementation with high doses of multiple micronutrients may improve the efficacy of radiation therapy by increasing tumor response and decreasing some of its toxicity on normal cells. The other hypothesis suggests that antioxidants will destroy free radicals that are generated during radiotherapy and would thus protect cancer cells against radiation damage. Both hypotheses are based on different conceptual frameworks that are derived from results obtained from specific experimental designs [17]. Both may be correct. Unfortunately, there are only few studies which have addressed micronutrient-related issues. It was shown that multivitamins do not improve radiation-related fatigue in patients with breast cancer [18]. Radiotherapy for breast cancer was also found to have no influence on selenium serum levels in contrast to previously held beliefes that radiotherapy would aggravate existing deficiencies [19]. However, a nonbreast cancer specific systematic review on selenium supplementation during radiotherapy found that it may protect healthy tissues and reduce the side effects of treatment [20]. This is in line with the formerly cited review which stated that antioxidants and other nutrients do not interfere with radiation therapy $[15,16]$.

\section{Micronutrients during Hormone Treatment of Breast Cancer}

Similar to chemotherapy and radiation therapy, there is evidence that micronutrients may improve efficacy and side effects of hormonal therapy. As shown above, vitamin E may alleviate hot flashes which are frequently the result of tamoxifen or aromatase inhibitors. Micronutrients may also improve the function of treatment. It was shown that there is a growth inhibition synergy and reversal of tamoxifen resistance by combination of selenium with tamoxifen [21]. Unfortunately, no clinical studies have addressed this and other interesting topics.

\section{Potential Side Effects of Micronutrients}

Micronutrients are needed by the human body only in small quantities. Within the framework of CAM, micronutrients are administered in normal doses but often also in high or very high doses. Still, many physicians believe in linear doseresponse relationships and believe 'a lot helps a lot'. There is increasing evidence that there are many U-shaped associations between dose and effect in the field of oncology. As a consequence, both low and high levels of a substance may lead to increased cancer incidence or recurrence whereas only normal levels are associated with lower cancer incidence and lower risk of recurrence. This hypothesis has been confirmed with regard to several macronutrients (proteins, lipids, carbo- 
hydrates) and their influence on breast cancer recurrence [22]. Recently, such a relationship was shown for vitamin D3 where both deficiency and a high concentration of calcidiol were found to increase cancer risk, and antioxidants to increase skin cancer risk [23, 24]. But such relations are not restricted to the field of oncology; they also hold true for serum selenium and peripheral arterial disease [25]. Regarding certain essential elements, it seems that two thresholds exist in an individual for adverse effect, one at low doses for undersupply, and another at high doses for toxicity [26].

Micronutrients also influence chemotherapy. In in vitro systems, selenium enhanced the chemotherapeutic effect of paclitaxel and doxorubicin [27]. Similarly, vitamin C was found to improve the antineoplastic activity of doxorubicin, cisplatin, and paclitaxel in human breast carcinoma cells in vitro [28]. So far, it is unknown how this enhancement acts on healthy tissues and in how far this leads to increased efficacy and/or toxicity. Clinical studies are lacking.

Since micronutrients are also frequently used in high doses and in combination with each other, there is the question of potential interaction effects between various micronutrients. A study on this subject found no improved breast cancer-specific survival and disease-free survival times for the vitamin/ mineral treated group over those for the controls [29]. The Kaplan-Meier curves in the referred work suggest worse survival with high-dose micronutrients.

\section{Conclusions}

At the present time, it is virtually impossible to give an answer to the question of whether micronutrients should be recom- mended for cancer patients or not. The simple reason for this is the lack of significant studies on the subject. Future research must assess whether cancer patients have different nutritional requirements compared to healthy people and if so determine the requirements during the various treatment options (surgery, chemotherapy, radiotherapy, hormonal therapy etc.) and disease stages (adjuvant or palliative setting). Furthermore, it seems important to determine the working mechanism of certain drugs and to investigate whether they are impaired or enhanced by certain micronutrients. On the basis of such work, it could be possible to develop reasonable schedules for the administration of micronutrients in the field of oncology, and in particular breast cancer. Until such knowledge exists it seems reasonable to avoid arbitrary high-dose administration of micronutrients. Whether a supplementation of normal doses should be supported or not remains unclear but it seems that it is acceptable to some degree. However, since many cases of breast cancer can be cured, the effects of micronutrient administration on other diseases must also be considered. A recent review [30] of the topic provides no evidence to support the use of micronutrients for primary or secondary prevention. Vitamin A, beta-carotene, and vitamin $\mathrm{E}$ administration were considered to increase mortality. The authors conclude that antioxidant supplements need to be considered medicinal products and should undergo sufficient evaluation before marketing [30]. This conclusion most definitely also applies to the use of antioxidants in breast cancer.

\section{Conflict of Interest}

There is no conflict of interest.

\section{References}

1 Ramakrishnan U: Prevalence of micronutrient malnutrition worldwide. Nutr Rev 2002;60:S46-52.

2 Rock CL: Multivitamin-multimineral supplements: who uses them? Am J Clin Nutr 2007;85(suppl): 277S-279S.

$>3$ Greenlee H, Hershman DL, Jacobson JS: Use of antioxidant supplements during breast cancer treatment: a comprehensive review. Breast Cancer Res Treat 2009;115:437-452.

4 Chung M, Balk EM, Brendel M, Ip S, Lau J, Lee J, Lichtenstein A, Patel K, Raman G, Tatsioni A Terasawa T, Trikalinos TA: Vitamin D and calcium: a systematic review of health outcomes. Evid Rep Technol Assess (Full Rep) 2009;183:1-420.

$\checkmark 5$ Gissel T, Rejnmark L, Mosekilde L, Vestergaard P: Intake of vitamin D and risk of breast cancer - a meta-analysis. J Steroid Biochem Mol Biol 2008;111:195-199.

6 Grant WB, Garland CF, Gorham ED: An estimate of cancer mortality rate reductions in Europe and the US with 1,000 IU of oral vitamin D per day. Recent Results Cancer Res 2007;174:225-234.
7 Alkhenizan A, Hafez K: The role of vitamin E in the prevention of cancer: a meta-analysis of randomized controlled trials. Ann Saudi Med 2007;27:409-414.

8 Druesne-Pecollo N, Latino-Martel P, Norat T, Barrandon E, Bertrais S, Galan P, Hercberg S: Beta-carotene supplementation and cancer risk: a systematic review and metaanalysis of randomized controlled trials. Int J Cancer 2010;127:172-184.

$\checkmark 9$ Larsson SC, Giovannucci E, Wolk A: Folate and risk of breast cancer: a meta-analysis. J Natl Cancer Inst 2007;99:64-76.

10 Navarro Silvera SA, Rohan TE: Trace elements and cancer risk: a review of the epidemiologic evidence. Cancer Causes Control 2007;18:7-27.

11 Ladas EJ, Jacobson JS, Kennedy DD, Teel K, Fleischauer A, Kelly KM: Antioxidants and cancer therapy: a systematic review. J Clin Oncol 2004; 22:517-528.

12 Borek C: Dietary antioxidants and human cancer. Integr Cancer Ther 2004;3:333-341.

13 Goodwin PJ, Ennis M, Pritchard KI, Koo J, Hood $\mathrm{N}$ : Prognostic effects of 25-hydroxyvitamin D levels in early breast cancer. J Clin Oncol 2009;27:37573763.
4 Block KI, Koch AC, Mead MN, Tothy PK Newman RA, Gyllenhaal C: Impact of antioxidant supplementation on chemotherapeutic toxicity: a systematic review of the evidence from randomized controlled trials. Int J Cancer 2008;123:1227-1239.

15 Simone CB 2nd, Simone NL, Simone V, Simone $\mathrm{CB}$ : Antioxidants and other nutrients do not interfere with chemotherapy or radiation therapy and can increase kill and increase survival, Part 1. Altern Ther Health Med 2007;13:22-28.

16 Simone CB 2nd, Simone NL, Simone V, Simone $\mathrm{CB}$ : Antioxidants and other nutrients do not interfere with chemotherapy or radiation therapy and can increase kill and increase survival, Part 2. Altern Ther Health Med 2007;13:40-47.

17 Prasad KN, Cole WC, Kumar B, Che Prasad K: Pros and cons of antioxidant use during radiation therapy. Cancer Treat Rev 2002;28:79-91.

18 De Souza Fêde AB, Bensi CG, Trufelli DC, de Oliveira Campos MP, Pecoroni PG, Ranzatti RP Kaliks R, Del Giglio A: Multivitamins do not improve radiation therapy-related fatigue: results of a double-blind randomized crossover trial. Am J Clin Oncol 2007;30:432-436. 
19 Fraunholz I, Eberlein K, Schopohl B, Böttcher HD, Rödel C: Selenium levels during the course of radiotherapy. No influence of irradiation on blood selenium concentration. Strahlenther Onko 2008;184:411-415.

20 Tabassum A, Bristow RG, Venkateswaran V: Ingestion of selenium and other antioxidants during prostate cancer radiotherapy: a good thing? Cancer Treat Rev 2010;36:230-234.

21 Li Z, Carrier L, Rowan BG: Methylseleninic acid synergizes with tamoxifen to induce caspase-mediated apoptosis in breast cancer cells. Mol Cancer Ther 2008;7:3056-3063.

22 Goodwin PJ, Ennis M, Pritchard KI, Koo J, Trudeau ME, Hood N: Diet and breast cancer: evidence that extremes in diet are associated with poor survival. J Clin Oncol 2003;21:2500-2507.

23 Tuohimaa P: Vitamin D, aging, and cancer. Nutr Rev 2008;66(10 suppl 2):S147-52.
24 Bleys J, Navas-Acien A, Laclaustra M, PastorBarriuso R, Menke A, Ordovas J, Stranges S, Guallar E: Serum selenium and peripheral arterial disease: results from the national health and nutrition examination survey, 2003-2004. Am J Epidemiol 2009;169:996-1003.

25 Van der Pols JC, Heinen MM, Hughes MC, Ibiebele TI, Marks GC, Green AC: Serum antioxidants and skin cancer risk: an 8-year communitybased follow-up study. Cancer Epidemiol Biomarkers Prev 2009;18:1167-173.

26 Douron M: U-shaped dose-response curves: implications for risk characterization of essential elements and other chemicals. J Toxicol Environ Health A 2010;73:181-186.

27 Vadgama JV, Wu Y, Shen D, Hsia S, Block J: Effect of selenium in combination with Adriamycin or Taxol on several different cancer cells. Anticancer Res 2000;20:1391-1414.
28 Kurbacher CM, Wagner U, Kolster B, Andreotti PE, Krebs D, Bruckner HW: Ascorbic acid (vitamin C) improves the antineoplastic activity of doxorubicin, cisplatin, and paclitaxel in human breast carcinoma cells in vitro. Cancer Lett 1996;103:183-189.

29 Lesperance ML, Olivotto IA, Forde N, Zhao Y, Speers C, Foster H, Tsao M, MacPherson N, Hoffer A: Mega-dose vitamins and minerals in the treatment of non-metastatic breast cancer: an historical cohort study. Breast Cancer Res Treat 2002;76:137-143.

30 Bjelakovic G, Nikolova D, Gluud LL, Simonett RG, Gluud C: Antioxidant supplements for prevention of mortality in healthy participants and patients with various diseases. Cochrane Database Syst Rev 2008;(2):CD007176. 